\title{
Factors affecting mortality in children with dilated cardiomyopathy
}

\author{
Muhammed Nurullah Sabaz, Alper Akın², Meki Bilici², Fikri Demir², Mehmet Türe², \\ Hasan Balık ${ }^{2}$ \\ ${ }^{2}$ Division of Pediatric Cardiology, ${ }^{1}$ Department of Pediatrics, Dicle University Faculty of Medicine, Diyarbakır, Turkey. \\ E-mail: alperakin1@hotmail.com
}

Received: 31st July 2018, Revised: 8th December 2018, Accepted: 15th December 2018

SUMMARY: Sabaz MN, Akın A, Bilici M, Demir F, Türe M, Balık H. Factors affecting mortality in children with dilated cardiomyopathy. Turk J Pediatr 2019; 61: 485-492.

Dilated cardiomyopathy (DCMP) is a heart disease with high mortality rates that is often seen in children. Genetic and infectious reasons are primary in the etiology. The aim of this study was to investigate the etiology of DCMP and the parameters predicting mortality. A retrospective examination was made of 37 patients diagnosed with DCMP between January 2012 and October 2016. Data were recorded from the patient files of age, gender, complaints on presentation, findings of the physical examination, laboratory test results, echocardiography and electrocardiography findings at the time of diagnosis. These parameters were then compared between the surviving and nonsurviving patients.

The patients comprised 21 males with a mean age of $27.50 \pm 50$ months. Diagnosis was made at the age of $<12$ months in $67.6 \%$ patients. Within mean 8 months of diagnosis, $16.2 \%$ of the patients were lost to mortality and $83.8 \%$ of the patients survived. In $83.3 \%$ of the non-surviving patients and in $29 \%$ of the surviving patients, sinus tachycardia was present at the time of diagnosis $(\mathrm{p}=0.023)$. Corrected QT (QTc) at the time of diagnosis was longer in the non-surviving patients $(\mathrm{p}=0.007)$. On ECG, the rate of ST-T wave change was higher in the non-surviving patients $(80 \%$ vs. $17.8 \%, \mathrm{p}=0.012)$.

In conclusion, a significant proportion of the patients were diagnosed below the age of one year. In the non-surviving patients, as sinus tachycardia and ischaemic changes on ECG were seen more often and the QTc was longer, these findings could be considered to be predictors of mortality.

Key words: dilated cardiomyopathy, child, myocarditis.

Dilated cardiomyopathy (DCMP) is a type of cardiomyopathy seen primarily as left ventricle dilation but there may also be dilation of both ventricles and heart failure. ${ }^{1}$ The incidence of cardiomyopathy has been reported as $4.8 / 100,000$ in infants and $1.3 / 100,000$ in children aged $<10$ years, and DCMP constitutes approximately $60 \%$ of these cases. ${ }^{2}$
The leading causes in the etiology are idiopathic, followed by myocarditis, coronary artery disease and other reasons. Familial inheritance is seen in $30-48 \%$ of all DCMP patients demonstrating the importance of genetic transfer. ${ }^{3}$ The prognosis of the disease is not good. Survival rates have been reported as $63 \%-90 \%$ for 1 year and $20 \%$ $80 \%$ for 5 years. ${ }^{4}$ As the prognosis of DCMP 
patients is not good, patients must be closely monitored after diagnosis and the factors affecting prognosis must be well considered. The aim of this study was to examine patients diagnosed with DCMP and thereby investigate the etiology and factors that could predict mortality.

\section{Material and Methods}

The study included a total of 37 patients, aged 7 months-17 years, who were diagnosed with dilated cardiomyopathy (DCMP), were admitted and followed up in the Paediatric Cardiology Department of Dicle University between January 2012 and October 2016. The patient records were examined for data on age, gender, complaints on presentation, consanguineous status of parents, familial history, physical examination findings, laboratory test results, echocardiography (ECHO) and electrocardiography (ECG) findings at the time of diagnosis, results of cardiac catheterisation if applied and the most recent clinical status.

The patients were separated into 2 groups according to the DCMP etiology as those with idiopathic DCMP or other causes. The patients were also separated into 2 groups as survivors and non-survivors and the relationships between these groups and the other parameters were also examined.

Approval for the study was granted by the Etthics Committee of Dicle University (Decision no: 345, dated: 16.12. 2016).

Statistical analyses of the data obtained were made using SPSS vn. 18.0.0 software. Conformity of the data to normal distribution was assessed using the Shapiro-Wilks test. In the comparison between 2 groups of continuous variables with normal distribution, the Independent Student's t-test was used and the Mann Whitney U-test was applied for groups not showing a normal distribution. To determine relationships between variables, Pearson Correlation analysis was applied. The Pearon Chi-square test and Fisher's Exact test were used for categorical variables. Measurable parameters were reported as mean \pm standard deviation (SD) and categorical variables as number (n) and percentage (\%). A value of $\mathrm{p}<0.05$ was accepted as statistically significant.

\section{Results}

The patients comprised 21 (56\%) males and 16 (44\%) females with a mean age of $27.50 \pm 50$ months (7 months-17 years). Body weight at the time of diagnosis was $10.6 \pm 10.9 \mathrm{~kg}$. There was parental consanguinity in $17(46 \%)$ patients and a familial history of DCMP in 4 (10.8\%) patients. Diagnosis was made at the age of $<12$ months in $25(67.6 \%)$ patients, at 13 months- 5 years in 7 (18.9\%), and $>5$ years in $5(13.5 \%)$.

In the month before diagnosis, a history of upper respiratory tract infection (URTI) was determined in 27 (73\%) patients, acute gastroenteritis (AGE) in $6(16 \%)$ and both URTI and AGE in 4 (11\%). The complaints on presentation and physical examination findings at the time of diagnosis are shown in Table I.

In 10 patients, viral etiological evaluation could not be performed and in 21 (56.8\%) patients, no etiology could be determined. Cytomegalovirus was determined in three patients, rubella in one and influenza $\mathrm{A}$ (H1N1) in one. In six patients, there was bacteriological production in either one of the blood and pleural fluid cultures. These patients were evaluated with DCMP secondary to myocarditis associated with infectious reasons. The etiologies of the patients are shown in Table II. The laboratory test results of the patients on first presentation are shown in Table III.

In the transthoracic ECHO examinations, mean left ventricle end-diastole diameter (LVEDd) was determined as $41.57 \pm 10.95 \mathrm{~mm}$, mean left ventricle end-systole diameter (LVESd) as $32.4 \pm 10 \mathrm{~mm}$, and mean left ventricular fractional shortening (LVFS) as $19.5 \pm 5 \%$. At the time of diagnosis, mean left ventricle ejection fraction (LVEF) was determined as $38.9 \pm 9.2 \%$ (range, $20-56 \%$ ) and at the end of 1-59 months follow-up (median 27 months), the final mean LVEF value was $58.1 \pm 12.9 \%$ (range, $28-76 \%$ ). In 20 (54\%) patients, normal LVEF levels (range, 56-78\%) were obtained. 
Table I. Complaints on Presentation and Physical Examination Findings at the Time of Diagnosis.

\begin{tabular}{lcc}
\hline & Number & $\%$ \\
\hline Complaints on presentation* & 3 & 8 \\
No complaint & 17 & 46 \\
Shortness of breath & 17 & 46 \\
Cough & 13 & 35 \\
Fever & 6 & 16 \\
Not suckling & 5 & 13 \\
Vomiting & 2 & 5 \\
Sweating & 3 & 8 \\
Bruising & 3 & 8 \\
Palpitations & 12 & 32 \\
Other complaints** & & \\
Physical examination findings* & 26 & 70 \\
Cardiac murmur & 15 & 40 \\
Pulmonary rales & 14 & 38 \\
Tachycardia & 14 & 38 \\
Tachypnea & 5 & 14 \\
Hepatomegaly & 4 & 11 \\
Reduced pulmonary sounds & 2 & 5 \\
Oedema & 8 & 22 \\
Other physical examination findings*** & & \\
\hline
\end{tabular}

*There were patients with more than one complaint and physical examination finding

** Diarrhea, listlessness, wheezing, chest pain, headache

*** Hyperemia in the oropharynx, hypertension, splenomegaly, retarded neuromotor development

Table II. The Etiology of The Cardiomyopathy.

\begin{tabular}{|c|c|c|}
\hline Etiology & Number & $\%$ \\
\hline Idiopathic & 21 & 56.8 \\
\hline Infectious myocarditis & 9 & 24.3 \\
\hline Cytomegalovirus & 3 & 30 \\
\hline Rubella & 1 & 10 \\
\hline Influenza A (H1N1) & 1 & 10 \\
\hline Bacterial agent & 4 & 44 \\
\hline Chronic renal failure & 3 & 8.1 \\
\hline $\begin{array}{l}\text { Metabolic disease (fatty acid oxidation } \\
\text { defect) }\end{array}$ & 1 & 2.7 \\
\hline Doxorubicin & 1 & 2.7 \\
\hline Aortic coarctation & 1 & 2.7 \\
\hline ALCAPA & 1 & 2.7 \\
\hline Total & 37 & 100 \\
\hline
\end{tabular}

ALCAPA: Anomalous Left Coronary Artery From the Pulmonary Artery 
Table III. Laboratory Test Results of The Patients on First Presentation.

\begin{tabular}{lc}
\hline Laboratory test & Result* \\
\hline Hemoglobin $(\mathrm{gr} / \mathrm{dl})$ & $10.4 \pm 1.5$ \\
Leukocytes $\left(\mathrm{mm}^{3}\right)$ & $12051 \pm 4757$ \\
Thrombocytes $(\mathrm{mg} / \mathrm{dl})$ & $361135 \pm 132000$ \\
Urea $(\mathrm{mg} / \mathrm{ld})$ & $29.54 \pm 31.15$ \\
Creatinine $(\mathrm{mg} / \mathrm{dl})$ & $0.59 \pm 0.56$ \\
Uric acid $(\mathrm{mg} / \mathrm{dl})$ & $5.6 \pm 2.9$ \\
Sodium $(\mathrm{mg} / \mathrm{dl})$ & $136.6 \pm 3.5$ \\
Calcium $(\mathrm{mg} / \mathrm{dl})$ & $9.2 \pm 0.95$ \\
Glucose $(\mathrm{mg} / \mathrm{dl})$ & $90.3 \pm 17.5$ \\
ALT $(\mathrm{IU})$ & $95.1 \pm 285$ \\
AST $(\mathrm{IU})$ & $192.2 \pm 597.3$ \\
CK $(\mathrm{mg} / \mathrm{dl})$ & $390 \pm 844.5$ \\
LDH $(\mathrm{mg} / \mathrm{dl})$ & $636 \pm 1060$ \\
Troponin $(\mathrm{ng} / \mathrm{ml})$ & $0.56 \pm 1.32$ \\
CK-MB (ng/ml) & $13.3 \pm 17.2$ \\
Albumin (mg/dl) & $3.5 \pm 0.47$ \\
CRP (mg/dl) & $1.1 \pm 2.36$ \\
Erythrocyte Sedimentation & $8.55 \pm 7.33$ \\
rate (mm/hour) &
\end{tabular}

* Mean \pm standard deviation

ALT: Alanine aminotransferase; AST: Aspartate aminotransferase; CK: Creatinine kinase; $\mathrm{CK}-\mathrm{MB}$ : Creatinine kinase-MB; CRP: C-reactive protein; $\mathrm{LDH}$ : Lactate dehydrogenase

Mortality was seen in $6(16.2 \%)$ patients at 2-33 months (median 8 months) after diagnosis, and 31 (83.8\%) survived. Mortality was seen in three patients aged $<12$ months and in three patients aged 5 years or older. The mortality rate of those aged $\geq 5$ years was statistically significantly higher than that of those aged $<12$ months $(\mathrm{p}<0.05)$. In $4(67 \%)$ of the 6 patients with mortality, death was determined to have occurred within one year of diagnosis.

The cases were separated into 2 groups as non-survivors (Group I) and survivors (Group II) and characteristics were compared between the groups. In Group I, 3 (50\%) patients were diagnosed at the age of $<12$ months and 3 $(50 \%)$ at the age of $\geq 5$ years; there were no patients in the $1-5$ years age group. In Group II, diagnosis was made at the age of $<12$ months in $22(71 \%)$ patients, at 13 months- 5 years in $7(23 \%)$ and $>5$ years in $2(6 \%)$.

The complaints on presentation and the physical examination findings of Groups I and II were compared. No statistically significant difference was determined between the groups in respect to complaints on presentation. In the evaluation of the physical examination findings, sinus tachycardia confirmed with ECG was present at the time of diagnosis in $5(5 / 6 ; 83.3 \%)$ and heart rate was within the normal limits for age in $1(16.7 \%)$ of the non-surviving patients. Sinus tachycardia was determined in 9 (29\%) and heart rate within the normal limits for age in $22(71 \%)$ of the surviving patients. Of the 14 patients determined with sinus tachycardia at the time of diagnosis, $9(64.3 \%)$ survived and 5 $(35.7 \%)$ did not survive and of the 23 patients not determined with sinus tachycardia at the time of diagnosis, 22 (95.7\%) survived and $1(4.3 \%)$ did not survive. Sinus tachycardia at the time of diagnosis was determined at a statistically significantly higher rate in Group I $(p=0.021)$. No statistically significant difference was determined between the groups in respect to other physical examination findings. The complaints on presentation and the physical examination findings of Groups I and II are shown in Table IV.

The 12-lead surface ECG findings were compared between the two groups. The corrected QT (QTc) according to the Bazzet formula was determined as median 0.40 secs (range, 0.39-0.41secs) in Group 1 and median 0.38 secs (range, $0.26-0.41$ secs) in Group II and the difference between the groups was statistically significant $(p=0.007)$. Pathological $\mathrm{Q}$ wave, ST segment and T-wave changes that suggest ischaemia were determined as statistically significantly greater in Group I than in Group II $(p=0.013)$. The ECG findings of both groups are shown in Tables V and VI. As the ECG records of 4 patients could not be accessed, the ECG data of 33 patients were examined.

The age of the patients, certain cardiac markers, ECHO and other ECG findings are shown in VI. In the evaluation of the ECHO findings, mean LVESd was determined as 
Table IV. Complaints on Presentation and Physical Examination Findings of Group I and Group II.

\begin{tabular}{lccccc}
\hline \multirow{2}{*}{ Complaint * } & \multicolumn{2}{c}{ Group I (n:6) } & \multicolumn{2}{c}{ Group II (n:31) } & \multirow{2}{*}{ P Value } \\
\cline { 2 - 5 } & $\mathrm{n}$ & $\%$ & $\mathrm{n}$ & $\%$ & \\
\hline Shortness of breath & 2 & 33.3 & 15 & 48.4 & 0.667 \\
Cough & 0 & 0 & 2 & 6.5 & 1.000 \\
Fever & 2 & 33.3 & 3 & 9.7 & 0.177 \\
Not suckling & 0 & 0 & 3 & 9.7 & 1.000 \\
Vomiting & 1 & 16.6 & 2 & 6.5 & 0.421 \\
Sweating & 1 & 16.6 & 5 & 16.1 & 1.000 \\
Bruising & 2 & 33.3 & 13 & 42 & 1.000 \\
Palpitations & 4 & 66.7 & 13 & 42 & 0.383 \\
Other complaints** & 3 & 50 & 9 & 29 & 0.728 \\
Physical examination* & & & & & \\
Murmur & 5 & 83.3 & 21 & 67.7 & 0.646 \\
Rales & 3 & 50 & 12 & 38.7 & 0.670 \\
Tachycardia & 5 & 83.3 & 9 & 29 & 0.021 \\
Tachypnea & 2 & 33.3 & 12 & 38.7 & 1.000 \\
Hepatomegaly & 1 & 16.7 & 4 & 12.9 & 1.000 \\
Oedema & 1 & 16.7 & 1 & 3.2 & 0.302 \\
Other *** & 3 & 50 & 5 & 16.1 & 0.510 \\
\hline
\end{tabular}

*There were patients with more than one complaint and physical examination finding

** Diarrhea, listlessness, wheezing, chest pain, headache

*** Hyperemia in the oropharynx, hypertension, splenomegaly, retarded neuromotor development

Table V. 12-Derivation Surface ECG Findings of Group I and Group II.

\begin{tabular}{lccccc}
\hline \multirow{2}{*}{ ECG finding } & \multicolumn{2}{c}{ Group I } & \multicolumn{2}{c}{ Group II } & \multirow{2}{*}{ P Value } \\
\cline { 2 - 5 } & $\mathrm{n}$ & $\%$ & $\mathrm{n}$ & $\%$ & \\
\hline Ventricular hypertrophy & $\mathrm{n}$ & $\%$ & $\mathrm{n}$ & $\%$ & \\
Left ventricle & 3 & 60 & 6 & 21.4 & \multirow{2}{*}{0.186} \\
Left and right ventricle & 0 & 0 & 3 & 10.8 & \\
No hypertrophy determined & 2 & 40 & 19 & 67.8 & \\
Total & 5 & 100 & 28 & 100 & \\
Findings of ischaemia & & & & & \\
Present & 4 & 80 & 5 & 17.8 & \multirow{2}{*}{0.013} \\
Absent & 1 & 20 & 23 & 82.2 & \\
Total & 5 & 100 & 28 & 100 & \\
\hline
\end{tabular}

$40.5 \pm 16.8 \mathrm{~mm}$ in Group I and $30.9 \pm 7.6 \mathrm{~mm}$ in Group II and the difference between the groups was statistically significant $(\mathrm{p}=0.029)$. The mean LVEF values were lower in Group I than in Group II, but the difference between the groups was not statistically significant $(p=0.071)$.

\section{Discussion}

The leading causes of DCMP have been reported as idiopathic reasons followed by myocarditis. ${ }^{5}$ De Boer et al. ${ }^{6}$ reported that DCMP was secondary to myocarditis in 14$22 \%$ of their patients and the majority were idiopathic. Similar to findings in literature, 
Table VI. Certain cardiac markers, ECHO and 12-Lead ECG Findings of Group I and Group II.

\begin{tabular}{lccc}
\hline Parameters & Group 1 & Group 2 & P value \\
\hline Age (months) & $5(1.3-72)$ & $7(0.5-204)$ & 0.433 \\
Troponin $(\mathrm{ng} / \mathrm{ml})^{*}$ & $0.085(0.04-0.13)$ & $0.9(0.01-0.92)$ & 0.751 \\
CK-MB (ng/ml)* & $25.4(4.26-46.5)$ & $7.18(0.72-54.33)$ & 0.356 \\
Electrocardiography & & & \\
$\quad$ QTc (ms) & $0.40(0.39-0.41)$ & $0.38(0.26-0.41)$ & 0.007 \\
Echocardiography & & & \\
$\quad$ LVEDd (mm) & $48.8 \pm 20.7$ & $40.1 \pm 7.7$ & 0.076 \\
$\quad$ LVESd (mm) & $40.5 \pm 16.8$ & $30.9 \pm 7.6$ & 0.029 \\
$\quad$ LVSF (\%) & $17.5 \pm 5.7$ & $19.9 \pm 4.9$ & 0.288 \\
$\quad$ LVEF (\%) & $31.8 \pm 8.9$ & $40.3 \pm 8.7$ & 0.071 \\
\hline
\end{tabular}

Data are presented as mean \pm SD

*median (range)

ALT: Alanine aminotransferase; AST: Aspartate aminotransferase; CK: Creatinine kinase; CK-MB: Creatinine kinase-MB; CRP: C-reactive protein; LVEF: left ventricle ejection fraction; LVSF: Left ventricle shortening fraction; LDH: Lactate dehydrogenase; LVEDd: left ventricle end diastole diameter; LVESd: left ventricle end systole diameter, QTc: corrected QT distance

the etiology could not be determined in $21(56.8 \%)$ of the current study patients. Of those where etiology was determined, myocarditis was similarly determined in a significant proportion. In a previous study, when endomyocardial biopsy was performed on patients diagnosed with DCMP, the disease was determined to be secondary to myocarditis in the majority of patients thought to be idiopathic. $^{7}$ As serological studies for causes of primary viral myocarditis (coxsackie virus, adenovirus, parvovirus B19) could not be performed in our hospital at the time of the study, it can be considered that the rate of viral myocarditis could have been higher and idiopathic reasons could have been lower.

In the current study, $27(73 \%)$ had URTI history within the previous month, $6(16 \%)$ patients had a history of AGE and 4 (11\%) had a history of both URTI and AGE. Although the rate of DCMP associated with myocarditis was found to be $24.3 \%$, the high rate of $73 \%$ of URTI history suggests that the rate of viral etiology could be higher than that determined in the study.

Various symptoms may develop in DCMP patients. Symptoms are generally related to insufficient perfusion and congestion. Respiratory system symptoms are frequent and listlessness, chest and abdominal pain, nausea and vomiting and delayed development are also frequently seen symptoms. ${ }^{8}$ In the current study, only 3 (8\%) patients had no complaints on first presentation, and in other patients the most common complaints were shortness of breath, cough and fever. In the physical examination evaluation of the current study, cardiac murmur, pulmonary rales, tachycardia, tachypnea, hepatomegaly, reduced pulmonary sounds and oedema were determined. These findings are expected in DCMP patients and develop as a result of pulmonary and systemic venous congestion.

The ECG examinations of patients diagnosed with DCMP are generally pathological. Left ventricle hypertrophy, ST-segment and T-wave changes are often observed and advanced anomalies, low voltage and pathological $Q$ wave may also be seen. ${ }^{8}$ A previous study showed ST-T changes in $50 \%$ of cases, left ventricle hypertrophy in $45 \%-70 \%$ and sinus tachycardia in several patients. ${ }^{1}$ In the ECG examinations of the current study, ventricular hypertrophy was observed in $88 \%$ of patients and findings of ischaemic changes in $64.9 \%$. In patients describing symptoms compatible with these ECG anomalies that are seen in the majority of patients, the ECG findings of ventricular hypertrophy and ischaemic changes should be a warning in respect to DCMP diagnosis. 
The 5-year survival rate has been reported as $50 \%$ in DCMP. ${ }^{9}$ Friedman et al. ${ }^{10}$ determined a mortality rate of $16 \%$ in children diagnosed with DCMP. In the current study, the mortality rate was determined as $16.2 \%$, similar to the rates in literature.

Of the 6 patients with mortality in the current study, $4(67 \%)$ died within one year of diagnosis. Survival of more than one year was seen in $90 \%$ of the patients. There are different data in the literature related to mortality according to age groups. While some authors have reported higher mortality rates before the age of the first year ${ }^{11,12}$, Burch et al. ${ }^{13}$ reported that mortality was higher in those over the age of 2 years. When mortality was examined according to age groups in the current study, the rate of non-survivors aged $\geq 5$ years was observed to be greater than that of survivors.

The mortality rate of patients with sinus tachycardia at the time of diagnosis was determined to be statistically significantly higher than the mortality rate of all the patients. A point requiring attention in DCMP is whether tachycardia has caused cardiomyopathy or whether tachycardia is caused by cardiomyopathy. ${ }^{14}$ In the current study, there was no supraventricular or ventricular tachycardia, but sinus tachycardia was present. This therefore suggested that sinus tachycardia had developed as a result of DCMP. Findings of ischaemia on ECG were determined at a statistically significantly higher rate in non-survivors than in survivors. A previous study reported that the prognosis and outcomes of ischaemic or irreversible cardiomyopathies were worse than in nonischaemic cardiomyopathy.Q In addition, the QTc values of the non-surviving patient group in the current study were determined as higher than those of the surviving patients. Previous studies have reported that the QTc value was increased in DCMP patients and this increase was a marker of poor prognosis in patients at different degrees. ${ }^{16,17}$

In conclusion, while a significant proportion of the patients diagnosed with DCMP were aged 12 months and younger, mortality was determined at a higher rate in those diagnosed at age 5 years and over. No significant difference was determined between survivors and non-survivors in respect of complaints on presentation, physical examination findings and laboratory test values, whereas the presence of sinus tachycardia, findings of ischaemia and prolonged QTC on ECG were parameters predicting mortality. Therefore, it must be emphasised that there should be close monitoring of children diagnosed with DCMP in respect to ECG findings.

\section{Acknowledgement}

This manuscript is produced from the thesis of first author under the supervision of the second author.

\section{REFERENCES}

1. Dec GW, Fuster V. Idiopathic dilated cardiomyopathy. N Engl J Med 1994; 331: 1564-1575.

2. Nugent AW, Daubeney PE, Chondros P, et al; National Australian Childhood Cardiomyopathy Study. The epidemiology ofchildhood cardiomyopathy in Australia. N Engl J Med 2003; 348: 1639-1646.

3. Jefferies JL, Towbin JA. Dilated cardiomyopathy. Lancet 2011; 375: 752-762.

4. Taliercio CP, Seward JB, Driscoll DJ, Fisher LD, Gersh BJ, Tajik AJ. Idiopathic dilated cardiomyopathy in the young: clinical profile and natural history. J Am Coll Cardiol 1985; 6: 1126-1131.

5. Wilkinson JD, Sleeper LA, Alvarez JA, Bublik N, Lipshultz SE; The Pediatric Cardiomyopathy Study Group. The pediatric cardiomyopathy registry 19952007. Prog Pediatr Cardiol 2008; 25: 31-36.

6. Den Boer SL, Meijer RP, van Iperen GG, et al Evaluation of the diagnostic work-up in children with myocarditis and idiophathic dilated cardiomyopathy. Pediatr Cardiol 2015; 36: 409-416.

7. Dec GW Jr, Palacios IF, Fallon JT, et al. Active myocarditis in the spectrum of acute dilated cardiomyopathies. Clinical features, histologic correlates, and clinical outcome. N Engl J Med 1985; 312: 885-890.

8. Moss and Adam's Heart Disease In Infants, Children and Adolescents: Including the fetüs and young adult. Allen HD, Shaddy RE, Penny DJ, Cetta F, Feltes TF. In: Lin KY and Rossano JW, Dilated cardiomyopathy. by Volters Kluver (9th ed) 2016: 1283-1295

9. Towbin JA, Lowe AM, Colan SD, et al. Incidence, causes, and outcomes of dilated cardiomyopathy in children. JAMA 2006; 296: 1867-1876.

10. Friedman RA, Moak JP, Garson A Jr. Clinical cause of idiopathic dilated cardiomyopathy in children. J Am Coll Cardiol 1991; 18: 152-156. 
11. Tsirka AE, Trinkaus $\mathrm{K}$, Chen SC, et al. Improved outcomes of pediatric dilated cardiomyopathy with utilization of heart transplantation. J Am Coll Cardiol 2004; 44: 391-397.

12. Arola A, Tuominen J, Ruuskanen O, Jokinen E. Idiopathic dilated cardiomyopathy in children: prognostic indicators and outcome. Pediatrics 1998; 101(3 Pt 1): 369-376.

13. Burch M, Siddiqi SA, Celermajer DS, Scott C, Bull C, Deanfield JE. Dilated cardiomyopathy in children: determinants of outcome. Br Heart J 1994; 72: 246 250.

14. Aykan HH, Karagöz T, Akın A, İrdem A, Özer S, Çeliker A. Results of radiofrequency ablation in children with tachycardia-induced cardiomyopathy. Anatol J Cardiol 2014; 14: 625-630.
15. Nagarakanti R, Whellan D, Rubin S, Mather PJ. Reversible cardiomyopathies. Cardiol Rev 2007; 15: 178-183.

16. Baumert M, Czippelova B, Porta A, Javorka M Decoupling of QT interval variability from heart rate variability with ageing. Physiol Meas 2013; 34: 14351448.

17. Alonso JL, Martínez P, Vallverdú M, et al. Dynamics of ventricular repolarization in patients with dilated cardiomyopathy versus healthy subjects. Ann Noninvasive Electrocardiol 2005; 10: 121-128. 